\title{
The Empirical Study among Internal Control, Social Responsibility and Financial Performance based on Chinese Listed Food and Beverage Industry
}

\author{
Jiayi Chen \\ Adam Smith Business School, University of Glasgow, Glasgow, United Kingdom \\ Email:Jiayichen1015@outlook.com
}

\begin{abstract}
This study revisits a classic yet still an intriguing question regarding the relationship between corporate social responsibility (CSR) and corporate financial performance (CFP). To explore the potential influence factor between the mentioned two factor, it is necessary to take internal control quality (ICQ) into account. The relation will be achieved by testing the panel data of 81 listed Chinese food and beverage industry from 2011 to 2015. There are three estimation hypotheses concerning three relations: the positive association between ICQ and CFP, the positive relationship between CSR and CFP, and finally the intermediate effect of CSR on the ICQ and CFP. Overall, results demonstrate that both ICQ and CSR have a significant positive relationship with CFP based on a series indexes. Moreover, the mediator effect has been mainly verified by the regression model according to the weight change of ICQ in the model.
\end{abstract}

Keywords: ICQ; CSR; CFP; intermediate effect

\section{Introduction}

\subsection{Background}

In recent years, the issue of purchase limitation on milk powder in Hong Kong has led to the issue of food safety becoming a topic of debate. Consumers are now more focused on food safety while most enterprises are pursuing economic benefits but neglecting the well-being of the stakeholders. In China, a large number of studies on corporate social responsibility (CSR) are based on previous research and are at the basic stage. Both scholars and industries are concerned about the relationship between CSR and corporate financial performance (CFP) and whether efficient conduct of CSR has a positive influence on financial performance. Furthermore, insufficient internal control is to blame in the case of such incidents. Internal control, one of the main enterprise management methods, has a significant influence on the future development of an individual. An increasing number of corporations realize that the misconduct of CSR would not only damage the environment, cause wastage of resources, and lead to climate changes but also lead to shortage of consumers and even bankruptcy. With similar kinds of incidents occurring and increasing awareness among consumers, the whole society is paying attention to CSR. As a result, companies are considering disclosing their CSR reports to the public, which indicates that CSR is a key part of the internal control system. Besides, the ultimate goal of improving internal control quality (ICQ) is to achieve business objectives, namely to improve management, risk prevention, and control capabilities to ensure that enterprises continue operations while promoting corporate performance. Therefore, the relationship between CSR and CFP, internal control quality (hereafter, ICQ) and CFP, and ICQ and CSR will be explored in this paper.

\subsection{Aim and Purpose of the Research}

The purpose of this article is to determine whether there is intermediate effect between ICQ and CFP and whether the intermediate factor is CSR. Next, it will discuss the relationship among these three factors and provide recommendations for enterprises to include CSR into daily corporate governance. Firstly, this article examines empirical studies on CSR within the global contexts. Most of the studies only focus on two factors among the abovementioned three and analyse the one-way relation between 
CSR and CFP or ICQ and CFP. Moreover, the correlation is found to vary from industry to industry. This study explores the problem from a new perspective by constructing a new model and applying CSR as the intermediate factor to determine the correlation among the three factors. Secondly, this article looks at the willingness of a company to undertake CSR and include it in the ICQ by revealing how CSR impacts financial performance. Also, it recommends how corporations can cut down the management cost, accomplish their social duty, achieve optimal allocation of social resources and thus promote a social economy. Further, this study provides a reference to the government to issue new guidelines to help the industry behave more legally.

\subsection{Structure and Research Methods}

This study examined listed food and beverage companies in Shenzhen and Shanghai stock market between 2011 and 2015, focusing on the relation among CSR, ICQ, and CFP and the intermediate effect of CSR on ICQ and CFP. The article is divided into the following chapters: Chapter 1 illustrates the study background and the need to explore the relation between CSR, ICQ, and CFP as well as the contributions. In Chapter 2, the author will analyse the findings from previous studies to present the relationship among the variables. Chapter 3 will firstly clarify the definition of CSR, ICQ, and CFP and then briefly propose the relationships. Next, the research hypotheses will be proposed. In Chapter 4, the author will discuss the selection of samples and clarify the sources of the data as well as the measurement standards for CSR, ICQ, and CFP. Further, the control variables will be specified and an empirical model will be constructed. The description of regression models and descriptive statistics will be presented. Chapter 5 will present the conclusion, limitations of the study, and suggestions for future research and improvement.

\subsection{Contributions}

Previous empirical studies tested the relationship between CSR and CFP and also the relation between ICQ and CFP but the results have been inconsistent. In terms of CSR and CFP, while some studies found a positive relationship, others found a negative or neutral relationship (Aupperle et al., 1985). Also, these studies did not clarify how exactly CSR or ICQ is associated with CFP, i.e. positively, negatively, or neutrally. Some scholars like Bowman (1975) carried out empirical studies to determine the correlations but provided inconclusive results. Besides, the function of ICQ might be different from industry to industry.

As there is little evidence to support the fact that CSR plays an intermediate role in the ICQ-CFP relation in the food and beverage industry, this dissertation aims to make a contribution. As a result, this dissertation will not simplify the relationship between CSR and CFP and IC and CFP because a simplified relationship only captures a fraction of the issue. The result of empirical study does support the original hypothesis that CSR acts as the intermediator between ICQ and CFP. It also extends CSR, ICQ, and CFP literatures by illustrating the potential relationship among these three concepts. Due to the situation that few empirical studies focus on the intermediate function between CSR and CFP, this dissertation will fill up the gap in literature. This dissertation also looks at different theories to identify the different variables to accurately measure CSR. Besides, by proposing a new function of CSR, i.e. the mediator function of CSR, this study aims to address the issues in corporate strategy to some extent.

\section{Literature Review}

\subsection{The Relationship between ICQ and CFP}

Ashbaugh-Skaife et al. (2009) found that the more frequency a firm disclosed internal fraud, the more complicated situation it would face by constructing the internal control fraud index. Normally, the complex position contained the re-build of a firm, the risk of the asset and the violation of stock price. The stock price of a company is more likely to drop if the problem of ICQ gets severe. Ge and McVay (2005) and Mitchell (2007) stated that inefficient IC systems can make the stock prices volatile and the company would lose the power to attain more profits. The companies that are usually at risk are small 
size corporations, with more liabilities and financial risk. On the contrary, Beneish et al. (2008) and Ashbaugh-Skaife et al. (2009) thought that a proper series of measurements regarding internal control would result in a series of reaction, such as the changing of current retain on equity and management strategy. Positive ICQ can lower the cost of equity and promote the CFP, thus making an enterprise more competitive in the business market to some extent. Besides, when focusing on the relationship between the quality of earnings and ICQ, Doyle et al. (2007) thought there was a positive correlation between ICQ and the quality of earnings, which was confirmed by the cases of some companies whose earnings declined because of inefficient IC. Also, Chi-Yang Tseng (2007) found that good IC can enhance the management system of a firm, promote the earnings, and increase firm value.

Compared to foreign countries, there is less research on ICQ and CFP in the context of China. With the improvements in enterprise IC in recent years, the relation between IC and CFP has aroused the attention of the academia. The studies on the relation between ICQ and CFP can be divided into roughly two categories: the first one acknowledges the positive relationship between ICQ and CFP. On observing the level of corporate governance and IC, Tang (2012) found that corporations with efficient usage of resources and high level of IC have higher level of corporate governance, which is beneficial to the promotion of financial performance. The second category states that there is no obvious relation between ICQ and CFP. A study by Zheng et al. (2009) pointed out that there was no symbiotic relationship between corporate performance and corporate IC.

\subsection{The Relationship between CSR and CFP}

Since the 1970s, research on CSR has been attracting attention. There are three kinds of views among foreign scholars: the first view was that CSR has a negative effect on CFP. Friedman (1970) held the opinion that corporations spend both physically and spiritually when conducting CSR. The implement of CSR would inevitably avoid the waste of firm resources, the increase cost of operation and human resource. Thus, the revenue of the firm would reduce and financial performance would be negatively affected. Similarly, an enterprise with higher costs would experience loss from the fluctuating market and lose its competitive advantages. In addition, some foreign scholars focused on enterprise stock value when studying the relationship between CSR and CFP. Brummerl et al. (1991) used stock price and stock return performance as the measurement of financial performance and concluded that the firm would have negative influence on financial performance in by the investigation of a certain number of companies. Additionally, the extent of influence was of great difference varying from industry to industry. The second opinion was that CSR has a positive effect on CFP. Freeman (1984) argued that if a corporation meets the needs of stakeholders, there would be a positive impact on economic status and financial performance. In the long term, an enterprise can enhance its reputation and achieve higher performance by satisfying the interest of stakeholders first. Preston and O'Bannon (1997) adopted product, quality of service, community and society, duty, and reputation as indexes for assessment to explore three aspects of performance: attitude to the customer, the community, and the employees. They also applied investment, total asset, and return on net asset to measure financial performance among sample firms. Finally, it was summarised that there was a strongly positive relation between CSR and CFP. The third argument of some scholars indicated that there was no connection between CSR and CFP. Williams and Siegel (2000) found there was no connection in their empirical research and stated that the possible reason was that CSR has an intermediate effect on corporate revenue and costs. Aupperle et al. (1985) came to a conclusion that there was no statistically significant correlation between CSR and CFP in the short term or long term.

Compared to foreign countries, the research on CSR and CFP in the Chinese context gained momentum much later and the mainstream views were as follows:

Firstly, CSR would have a positive impact on CFP; Shen (2005) and Tao (2012) made a similar comment. Tao's found that there was not only a one-way relation but a two-way causality. Secondly, the relationship between CSR and CFP was not strong or negative in short-term financial performance; when taking into account the lag, there was a positive correlation in the long term. Li (2007) looked at the disclosed information of listed companies as a research object and used an empirical model to analyse the relationship between CSR and corporate value to find that they were negatively related. However, corporate value would not decline because of the fulfilment of CSR, but would have a positive impact on the enterprise. Kong and Li (2010) found that the CFP indicators and CSR indicators were 
significantly positive correlated. Moreover, the impact of CSR on CFP had a time lag and would elicit a significant response after the first several periods. The third opinion was that there is no significant correlation between CSR and CFP. Chen and Ma (2005) conducted an empirical test on the disclosure of CSR but the results showed that there was no significant correlation between social value and financial performance; besides, the value of enterprises varied in different industries.

\subsection{The Relationship between ICQ and CSR}

On one hand, CSR is a part of ICQ and if a company conduct its CSR well the rest factors of internal control would also be promoted. In the current system of ICQ in China, internal environment is the basis for other internal control factors, thus to promote the internal environment is to support the rest of other factors. According to the principal-agent theory, it is necessary for a company to perfect its ICQ for the sake of protecting the shareholders' benefits. For enterprises themselves, to fulfil CSR for the shareholders is the key to achieving ICQ. Specifically, internal control is essentially the detailed responsibility for shareholders. Based on stakeholder theory, shareholders, creditors and employees are part of the society and protecting their own benefits means to fulfil social responsibility in a narrow way. Creditors' conducting the responsibility, means the financial risk would be lower and the ability to refinancing would be higher. All the capital that enterprises needs would be affected positively and thus the efficiency and economic benefits would be promoted. A company's fulfilling the responsibility to employees would directly affect their attitudes and the efficiency. All in all, fulfilling various kinds of responsibility would obviously strengthen a good social fame and have positive effect on internal control.

The present research shows that direction of correlation between CSR and ICQ could be one-way or two-way. This means ICQ can guarantee the accomplishment of CSR; meanwhile, the achievement of CSR can help firms achieve effective IC. Besides, there is a difference between the general definition of CSR and that in the food and beverage industry. Knight et al. (2007) stated that food safety is directly related to daily life and human health, so CSR becomes the fundamental responsibility of food corporations. In addition, CSR in the food and beverage industry is not limited to product quality but includes the social environment. For the food and beverage industry, health and safety should be regarded as the main focus of CSR for the reason that food and beverage are directly linked to human health. However, all the responsibility is connected with internal control in food and beverage industry, so it means between ICQ and CSR, ICQ weights more.

\subsection{Conclusion and Hypothesis}

This article makes a brief conclusion of the existing literature regarding three kinds of relations: CSR and CFP, ICQ and CFP, CSR and ICQ. Due to the various measurements and the hardness of qualifying different variables, there is no unified conclusion.

However, based on the related literature about the effect of CSR and ICQ on CFP, a majority of scholars believe they are both in positive relationships. Besides, there are few studies including these three factors in one system to analyse the possible relations. Thus, the author put forward three hypotheses and these hypotheses will be tested in the following chapters.

H1: The impact of level of internal control on financial performance is positive effects.

H2: The relation of corporate social responsibility and financial performance is positive.

H3: Corporate social responsibility is the intermedia between internal control and financial performance.

\section{Research Design}

To analyse the relation between CSR, ICQ and CFP, an empirical study is used which has been broadly applied in previous literature. Chapter 3 clarifies the progress of data selection, variable measurement and model construction. Excel is used to store data, and SPSS (Statistic Package for Social Science) is used to conduct correlation and regression analysis.

\subsection{Sample and Data Collection}

This empirical study focuses on data on the Chinese listed food and beverage industry in Shanghai and 
Shenzhen stock market from 2011 to 2015. The data selection is from WIND and CSMAR, including financial reporting and internal governance disclosure. Also, the potential sample that lacked information of ROA, the elements of ICQ and CSR are removed. As a result, the adjusted data interval is from 2011 to 2015 and the final number of sample is 354(81 companies in total).

\subsection{Variable Measurement}

\subsubsection{Explained variable: CFP}

There are various kinds of indices that can measure the financial performance of a company for different sakes, such as ROE (accounting-based measurement), ROA (accounting-based measurement) and EPS (market-based measurement). The difference between two measurements is out of the differences of stakeholders, accounting-based measures focus on the reality finance figure while market-based measurements are from the aspect of shareholders' perspective and regarded as the ratio of return. Moreover, ROE is one of the key standards of testing for a listed Chinese company, if a firm's only pursuit is the attainment of ROE standard, it would be a close result in the performance of earnings control. As a result, ROA would be the appropriate choice to measure the corporate financial performance in this study.

\subsubsection{Explanatory variable: ICQ and CSR}

As referred to in the literature review, internal control, the status of internal control systems, based on corporate disclosure reports, asset security, strategy, operations, compliance. So the measurements of ICQ (Internal Control Quality) would be classified into five variables as X1, X2 , X3, X4 and X5. X1 means the level of legality, which could be measured by the frequency of administrative procedure and the administrative penalty. X2 means the facticity of the annual report through the opinion of annual corporate auditing. X3 means the efficiency of operating by calculating TAT (Total Asset Turnover). $\mathrm{X} 4$ means the result of operation by counting the operation return rate. X5 means the safety level of the asset through calculating the asset loss rate. The formula can be constructed: $\mathrm{ICQ}=\mathrm{X} 1 \times 20 \%+\mathrm{X} 2 \times 24 \%+\mathrm{X} 3 \times 16 \%+\mathrm{X} 4 \times 18 \%+\mathrm{X} 5 \times 22 \%$ (Chen and Liu, 2017). The different coefficient comes from a politic issue named: "The primary guidance of internal control between corporates". The more detailed illustration could be found in Table 1 .

Table 1. The standard of Internal Control measurement

\begin{tabular}{lllllllll}
\hline Object & Index & Code & Weight & \multicolumn{6}{c}{ Standard } \\
& & & & Excellent & Good & Neutral & Bad & Worse \\
\hline Legal & FOAP & X1 & $20 \%$ & 0 & 1 & 2 & 3 & $>3$ \\
FR & AO & X2 & $24 \%$ & S & CS & C & CE & D \\
OEY & TAT & X3 & $16 \%$ & 1 & 0.8 & 0.6 & 0.4 & 0.1 \\
OES & R\% & X4 & $18 \%$ & 23.5 & 18.1 & 11.5 & 2.7 & -3.3 \\
\hline
\end{tabular}

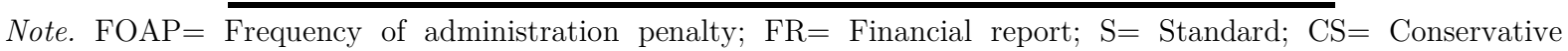
standard; $\mathrm{C}=$ Conservative; $\mathrm{CE}=$ Can't express; $\mathrm{D}=$ Doubt; $\mathrm{AO}=$ Auditing opinion; $\mathrm{OEY}=$ Operation efficiency; $\mathrm{TAT}=$ Total asset turnover; $\mathrm{OES}=$ Operation effectiveness; $\mathrm{R} \%=$ Revenue $\% ; \mathrm{AS}=$ Asset safety; $\mathrm{AIL}=\mathrm{Asset}$ impairment loss $\%$;

Moreover, the measurement of CSR is of difference between China and the foreign country. For example, international scholars measure corporate social responsibility through adopting the reputation index method, KLD index and corporate charity law to gauge the performance of corporate social responsibility. Meanwhile, national research is based on the stakeholder theory and improved by previous studies. There exists a common belief that the range of stakeholders contains: shareholder, employee, government, consumer, creditor and environment. The detailed description of variables could be found in Table 2 . 
Table 2. The definition of different variables

\begin{tabular}{llll}
\hline Type & & Variable & Code \\
\hline $\begin{array}{lll}\text { Dependent } \\
\text { Variable }\end{array}$ & & Return on asset & ROA \\
& & Internal control quality & ICQ \\
\hline \multirow{4}{*}{$\begin{array}{l}\text { Shareholder } \\
\text { variable }\end{array}$} & Earnings per share & EPS \\
& Employee & Employee profit level & EmpCR \\
& Government & Government contribution & GovCR \\
& Consumer & Cost of operation & CusCR \\
& Creditor & Cash flow to loan & CreCR \\
& Environment & Environment exposure & EnvCR \\
\hline \multirow{4}{*}{ Control variable } & Firm nature & & OWNER \\
& Firm size & & SIZE \\
& Leverage & & LEV \\
& Year & & YEAR \\
\hline
\end{tabular}

Note. $\mathrm{ROA}=\mathrm{Net}$ income/Total asset; $\mathrm{ICQ}=\mathrm{X} 1 \times 20 \%+\mathrm{X} 2 \times 24 \%+\mathrm{X} 3 \times 16 \%+\mathrm{X} 4 \times 18 \%+\mathrm{X} 5 \times 22 \%$; EPS $=$ (ProfitPreferred dividends)/Weight average common share; EmpCR=Employee paid/Operation income; GovCR=(Tax paid-Tax returned)/Operation; CusCR=Operation cost/Operation income; CreCR=Net cash flow/Loan; EnvCR=If exposed in social repport:1, if results in expense:1; OWNER=1 means state-owned, if not, 0; SIZE=Log of the total asset after the year; LEV=Loan/Asset.

\subsubsection{Control variables}

The control variables, in this case, would be the leverage, size, and ownership. The study will build three regression model based on panel data so that the sequence of year is the fixed variable.

\subsection{Model Construction}

Based on the hypothesis mentioned in literature review part, the author would construct three models as follows.

3.3.1 The regression model of internal control and financial performance: $\mathrm{ROA}=\alpha 0+\alpha 1$ ICQ $+\alpha 2$ SIZE $+\alpha 3 \mathrm{LEV}+\alpha 4 \mathrm{OWNER}+\Sigma \mathrm{YEAR}+\varepsilon$

H1: The impact of level of internal control on financial performance is positive effects.

3.3.2 The regression model of corporate social responsibility and financial performance: $\mathrm{ROA}=\beta 0+\beta 1 \mathrm{EPS}+\beta 2 \mathrm{EmpCR}+\beta 3 \mathrm{Gov} \mathrm{CR}+\beta 4 \mathrm{CusCR}+\beta 5 \mathrm{CreCR}+\beta 6 \mathrm{Env} \mathrm{CR}+\beta 7 \mathrm{SIZE}+\beta 8 \mathrm{LEV}+\beta 9 \mathrm{O}$ $\mathrm{WNER}+\Sigma \mathrm{YEAR}+\varepsilon$

H2: The relation of corporate social responsibility and financial performance is positive.

3.3.3 The regression model of the intermediary function of social responsibility: $\mathrm{ROA}=\gamma 0+\gamma 1 \mathrm{ICQ}+\gamma 2 \mathrm{EPS}+\gamma 3 \mathrm{EmpCR}+\gamma 4 \mathrm{GovCR}+\gamma 5 \mathrm{CusCR}+\gamma 6 \mathrm{CreCR}+\gamma 7 \mathrm{EnvCR}+\gamma 8 \mathrm{SIZE}+\gamma 9 \mathrm{LE}$ $\mathrm{V}+\gamma 10 \mathrm{OWNER}+\Sigma \mathrm{YEAR}+\varepsilon$

H3: Corporate social responsibility is the intermedia between internal control and financial performance.

\section{Data Analysis and Results}

\subsection{Descriptive Statistics}

Table 3 describes the key descriptive statistics (minimum value, maximum value, mean value and standard deviations) for the ROA and six independent variables and three control variables. In this table, the mean ROA of the sample companies was $0.091(\mathrm{SD}=0.107)$, which represents the overall financial performance. The maximum and minimum values were 0.4182 and -0.1899 , respectively. The above figures indicate the difference in total return on assets in this industry was low. The average ICQ of the samples was 0.745 , the maximum value was 1 and minimum, 0.328 , illustrating that the degree of ICQ between individual companies is quite different in the food and beverage industry. It is believed that the food and beverage industry has a higher level of profit with a mean EPS of 0.6857. However, 
the large standard deviation (1.56), minimum and maximum index values $(-0.8566,12.34)$ show that there is a big gap between different listed Chinese food and beverage companies in terms of the overall stock performance. This may be attributed to the difference in the nature and levels of their goods. The average EmpCR was $12.08 \%$, which was basically the same as the average level overall. The actual paid taxes and fees account for $11.38 \%$ of the operating income. Additionally, the mean value of CusCR was 0.5739, the minimum was 0.0778 , and the maximum was 0.9908 , indicating that the food and beverage firms have different operating costs. The mean of CreCR was 35.83\%, indicating the corporation's shortterm ability of solvency was weak. The EnvCR indicates the entire industry's disclosure of social responsibility report was $9.04 \%$. Concerning OwnCR, the proportion of nation-owned and non-nationowned is relatively average at the mean value of 0.5989 . The maximum and minimum values of SIZE were 24.685 and 19.4114 , respectively. The standard deviation (1.1102) was smaller than the mean value (21.8394), showing that the data of corporate size was stable. Finally, the mean value of LEV was 0.3789 , indicating that the industry's ability to pay its debts was sufficient.

Table 3. The descriptive statistics of variables

\begin{tabular}{cccccc}
\hline Variable & $\mathrm{N}$ & Min & Max & Mean & SD \\
\hline ROA & 354 & -.189900 & .418200 & .09097599 & .106952678 \\
X1 & 354 & .600000 & 1.000000 & .98813559 & .054021544 \\
X2 & 354 & .400000 & 1.000000 & .98644068 & .065940897 \\
X3 & 354 & .000000 & 1.000000 & .53954802 & .273194966 \\
X4 & 354 & .000000 & 1.000000 & .50790960 & .327743824 \\
X5 & 354 & .000000 & 1.000000 & .60406780 & .486846074 \\
ICQ & 354 & .328000 & 1.000000 & .74501921 & .140289536 \\
EPS & 354 & -.856600 & 12.340000 & .68567203 & 1.567614092 \\
EmpCR & 354 & .033200 & .424000 & .12079802 & .059528109 \\
GovCR & 354 & -.086200 & .428800 & .16152147 & .113845490 \\
CusCR & 354 & .077700 & .990800 & .57397486 & .194936300 \\
CreCR & 354 & -.636500 & 3.127400 & .35830395 & .574494573 \\
EnvCR & 354 & .000000 & 1.000000 & .09039548 & .287153386 \\
OWNER & 354 & .000000 & 1.000000 & .59887006 & .490820981 \\
SIZE & 354 & 19.411400 & 24.685000 & 21.83942373 & 1.110231277 \\
LEV & 354 & .027400 & .994700 & .37889859 & .209006182 \\
\hline Note. Valid & N=354 & & & &
\end{tabular}

\subsection{Correlation Analysis}

In the empirical study, the correlation between the variables was tested over the period of 2011-2015 (Table 4). As can be seen in Table 4, most of the independent variables and control variables have a positive correlation with ROA except EmpCR, CusCR, OWNER, and LEV. In terms of employees, the expenditure on security and training, welfare payments, and other unforeseen events may result in higher cost on employees. If a company fails to control the cost of procedure, the high costs will definitely have a negative effect on the scale of profits. The effect of nature of firm owner may vary from firm to firm. In this case, the benefits for nation-owned firms are obvious as they have a large capital to purchase materials than the non-state-owned ones but they may not provide products as per current trends. The influence of ownership is hard to determine without a detailed case study. The correlation coefficient of ICQ and ROA is 0.537 , at $1 \%$ significance level, indicating that a high level of ICQ promotes better CFP. In addition, the correlation between ROA and shareholders, government, environment, and creditor's responsibility is positive at $1 \%$ significance level, and the relationship between ROA and employees and consumers is negative at $1 \%$ significance level. Overall, the correlations above verify the initial hypothesis. 
Table 4. The correlations of variables

\begin{tabular}{llllllllllll}
\hline & ROA & ICQ & EPS & Emp & Gov & Cus & Cre & Env & OWN & SIZE & LEV \\
\hline ROA & 1 & - & - & - & - & - & - & - & - & - & - \\
ICQ & $.537^{* *}$ & 1 & - & - & - & - & - & - & - & - & - \\
EPS & $.652^{* *}$ & $.301^{* *}$ & 1 & - & - & - & - & - & - & - & - \\
Emp & $-.357^{* *}$ & $-.327^{* *}$ & $-.170^{* *}$ & 1 & - & - & - & - & - & - & - \\
Gov & $.495^{* *}$ & $.256^{* *}$ & $.442^{* *}$ & $.207^{* *}$ & 1 & - & - & - & - & - & - \\
Cus & $-.620^{* *}$ & $-.347^{* *}$ & $-.502^{* *}$ & $-.148^{* *}$ & $-.819^{* *}$ & 1 & - & - & - & - & - \\
Cre & $.342^{* *}$ & $.324^{* *}$ & $.242^{* *}$ & -0.065 & $.151^{* *}$ & $-.339^{* *}$ & 1 & - & - & - & - \\
& & & & 0.222 & 0.004 & & & & & & \\
Env & 0.006 & -0.006 & 0.018 & -0.052 & -0.053 & 0.082 & -0.034 & 1 & - & - & - \\
& 0.91 & 0.911 & 0.736 & 0.332 & 0.322 & 0.122 & 0.523 & & & & \\
OWN & -0.011 & -0.006 & $.117^{*}$ & -0.02 & 0.042 & 0.08 & $-.252^{* *}$ & $.218^{* *}$ & 1 & - & - \\
& 0.84 & 0.917 & 0.028 & 0.703 & 0.432 & 0.132 & 0 & 0 & & & \\
SIZE & $.338^{* *}$ & $.110^{*}$ & $.491^{* *}$ & $-.276^{* *}$ & $.231^{* *}$ & $-.189^{* *}$ & -0.091 & $.134^{* *}$ & $.277^{* *}$ & 1 & - \\
& & 0.038 & & & & & 0.088 & 0.012 & & & \\
LEV & $-.241^{* *}$ & $-.207^{* *}$ & $.164^{* *}$ & -0.076 & $.254^{* *}$ & $.368^{* *}$ & $-.521^{* *}$ & -0.031 & $.143^{* *}$ & $.176^{* *}$ & 1 \\
& & & 0.002 & 0.153 & & & & 0.561 & 0.007 & 0.001 & \\
\hline
\end{tabular}

Note. ${ }^{* *}$ Correlation is significant at the 0.01 level(2-tailed). ${ }^{*}$ Correlation is significant at the 0.05 level(2-tailed).

\subsection{Regression Results of ICQ and CFP}

To test the above three hypotheses, ordinary squares multiple regression analysis was carried out and the results are presented in Table 5, Table 6, and Table 7 . These tables illustrate the original results of this empirical research. According to Table 5, the F-statistic of the regression model of ICQ and CFP is 29.014 , the significance level $\mathrm{Sig}=0.000$, and adjusted $\mathrm{R}^{2}$ is 0.432 . The above figures show that this model has a relatively good explanatory power for this socio-economic research. It can be seen that the p-value is smaller than 1 , which indicates that there is a clear liner relationship among the variables. To be more precise, there is a positive relationship between ICQ and CFP at the 1\% level, so hypothesis H1 is accepted. The impact of ICA on the return on assets (ROA) was significant, with a positive correlation, thus validating the hypothesis H1. The size of enterprises (SIZE) and ROA showed significantly positive correlation, indicating that the size of the firm affects the yield of the net assets to a certain extent, and the increase in enterprise scale may be beneficial to ROA. The level of corporate debt (LEV) is negatively correlated with ROA, indicating that a high asset-liability ratio may be detrimental to the improvement in ROA because the addition of debt would increase the expense of financing activities and the cost of capital, resulting in lower financial performance. Ownership (OWNER) and ROA were negatively correlated, but not at a significant level, indicating the financial performance of state-owned corporations is inferior to that of non-state-owned ones and the government holding would probably lower the efficiency of business operation and affect the financial performance.

Table 5. Regression results of ICQ and CFP

\begin{tabular}{cccccc}
\hline \multirow{2}{*}{ Variable } & \multicolumn{2}{l}{ Unstandardized Coefficients } & Standardized Coefficients & t-value & \multirow{2}{*}{ Sig. } \\
\cline { 2 - 3 } & $\mathrm{B}$ & $\mathrm{SE}$ & $\mathrm{B}$ & & \\
\hline Beta & -.875 & .092 & .395 & -9.511 & .000 \\
ICQ & .314 & .035 & -.236 & 8.840 & .000 \\
LEV & -.124 & .023 & -.082 & -5.392 & .000 \\
OWNER & -.019 & .010 & .383 & -1.918 & .056 \\
SIZE & .038 & .004 & 8.590 & .000 \\
\hline $\mathrm{F}=29.014$ Sig $=0.000 \mathrm{R}$ Square $=0.432$ Adjusted R Square $=0.417 \mathrm{DW}=1.243$ &
\end{tabular}




\subsection{Regression Results for CSR and CFP}

Table 6 shows that the F-statistic of the regression model for CSR and CFP is 35.782, the significance level Sig $=0.000$, and the adjusted $\mathrm{R}^{2}$ is 0.58 . Thus, model explains the liner relationship between CSR and CFP. In addition, there is a positive relationship between CSR and CFP at 1\% level and hypothesis H2 is successfully tested. Further, earnings per share (EPS) and CFP show significant positive effect, indicating that the better accomplishment of CSR is beneficial for shareholders and CFP. However, the level of employee profitability (EmpCR) and CFP showed a significantly negative correlation, indicating that the overall burden of Chinese listed food and beverage firms has become heavier. Moreover, there is a negative correlation between the actual tax payment rate and CFP in the government's responsibility part (GovCR), which doubts that the financial performance of the enterprise is directly affected by the enterprise's incentive to exercise the tax liability. Also, this leads to the question of whether the government of China plays a significant role in the food and beverage industry or the industry is market-oriented. As for the consumer (CusCR), the operation cost ratio and CFP are negatively correlated, illustrating that the active implementation of the responsibility towards consumers would reduce the financial performance of enterprises because the benefits are transferred to the consumers. Regarding the environment (EnvCR), it is obvious that the disclosure of the environment is positively related to financial performance and it can be inferred that the more attention a company pays towards its duty to the environment the better its financial performance. Finally, cash flow liabilities ratio (CreCR) is positively related to the financial performance, indicating that the higher the cash flow liabilities ratio the stronger the ability of solvency. Additionally, creditor's interest is a guarantee of the financial performance of a firm.

Table 6. Regression results of CSR and CFP

\begin{tabular}{llllll}
\hline Variable & \multicolumn{2}{l}{ Unstandardized Coefficients } & Standardized Coefficients & t-value & Sig. \\
\cline { 2 - 4 } & $\mathrm{B}$ & $\mathrm{SE}$ & Beta & & \\
\hline Beta & -.002 & .099 & & -.023 & .982 \\
EPS & .022 & .003 & .334 & 7.166 & .000 \\
EmpCR & -.060 & .021 & -.105 & -2.874 & .004 \\
GovCR & -.090 & .061 & -.094 & -1.488 & .138 \\
CusCR & -.273 & .040 & -.478 & -6.906 & .000 \\
CreCR & .014 & .007 & .084 & 1.993 & .047 \\
EnvCR & .006 & .014 & .015 & .426 & .671 \\
OWNER & -.007 & .009 & -.031 & -.825 & .410 \\
SIZE & .014 & .005 & .138 & 3.039 & .003 \\
LEV & -.014 & .023 & -.027 & -.622 & .535 \\
\hline F=35.782 Sig=0.000 R Square=0.596 Adjusted R Square=0.58 DW=1.177 &
\end{tabular}

$\mathrm{F}=35.782 \mathrm{Sig}=0.000 \mathrm{R}$ Square$=0.596$ Adjusted R Square=0.58 DW=1.177

\subsection{Regression Results for ICQ, CSR, and CFP}

Table 7 shows that the F-statistic of the regression model of ICQ, CSR, and CFP is 53.702, the significance level $\mathrm{Sig}=0.000$, and adjusted $\mathrm{R}^{2}$ is 0.691 . After adding the intermediate variable CSR to the model of ICQ and CFP, the adjusted $\mathrm{R}^{2}$ was 0.609 , showing an increase by $46 \%$ when compared to the former model. This means the model was improved by adding the variable. Though the coefficient of ICQ dropped to 0.129, which is apparently lower than the former coefficient 0.314 , the result is still at the $1 \%$ significant level, indicating that CSR does play an intermediate role between ICQ and CFP. Thus, hypothesis H3 is valid. 
Table 7. Regression results of ICQ, CSR and CFP

\begin{tabular}{llllll}
\hline \multirow{2}{*}{ Variable } & \multicolumn{2}{l}{ Unstandardized Coefficients } & Standardized Coefficients & t-value & Sig. \\
\cline { 2 - 4 } & B & SE & Beta & & \\
\hline Beta & .119 & .093 & & 1.282 & .201 \\
ICQ & .129 & .028 & .169 & 4.638 & .000 \\
EPS & .021 & .003 & .310 & 7.685 & .000 \\
EmpCR & -.512 & .067 & -.285 & -7.581 & .000 \\
GovCR & .046 & .052 & .049 & .892 & .373 \\
CusCR & -.211 & .033 & -.385 & -6.469 & .000 \\
CreCR & .010 & .007 & .056 & 1.454 & .147 \\
EnvCR & .010 & .012 & .026 & .844 & .399 \\
OWNER & -.006 & .007 & -.026 & -.781 & .436 \\
SIZE & .003 & .004 & .028 & .693 & .489 \\
LEV & -.001 & .019 & -.003 & -.073 & .942 \\
\hline
\end{tabular}

$\mathrm{F}=53.702 \mathrm{Sig}=0.000 \mathrm{R}$ Square$=0.704$ Adjusted R Square=0.691 DW=1.226

\section{Conclusion}

\subsection{Findings}

On empirical analysis of the relationship among ICQ, CFP and CSR of Chinese listed corporations from the Shenzhen and Shanghai exchange stock market, the following conclusions were inferred: Firstly, ICQ is positively correlated with financial performance, in other words, the improvement of ICQ can improve CFP. Also, CSR and CFP showed a significantly positive correlation, indicating that the improved CSR practices led to better CFP. Moreover, when adding CSR to the original model, the impact of ICQ on corporate performance decreased significantly (from 0.395 to 0.169 ). In other words, CSR plays the role of a bridge between ICQ and CFP.

Meanwhile, we can conclude that both ICQ and CSR play an important role in enhancing CFP. First of all, given the significant positive relation between ICQ and CFP, the listed food and beverage firms in China should build up a functional ICQ system and pay attention to the basic structure of enterprise ICQ. It should take the profitability of enterprises and the cost of internal control into fully consideration before the establishment of enterprise organisational structure. Only in this way can a company maintain effective decentralisation and remain independent of the structural mechanism. Secondly, based on the significantly positive relationship between CSR and CFP, efforts should be made to enhance the CSR activities in those industries that are close to citizens' daily life. To become a firm with highly awareness of conducting CSR, it needs to strengthen the internal control system to enhance their own performance, and also focus on the value of corporate social responsibility culture of publicity. On the other hand, attention should be given to the implementation and publicity of CSR with the help of social media channels to build business reputation. All these efforts would ultimately lead to higher CFP.

\subsection{Limitations}

There are some limitations to this study. First of all, the measurement of ICQ is limited to the Chinese political guidance, so the results should be examined with caution for industries in other regions. Since this paper focuses on Chinese listed food and beverage firms, the definition and measurement of internal control should be some more specific. Besides, this dissertation did not look at industry specialisation. Secondly, the concepts and measurements of CSR and CFP were based on previous literatures rather than comprehensive self-thinking by the author, and this study only employs one financial variable to measure firm's financial performance, which may be insufficient to illustrate corporate financial performance thoroughly. Last but not the least, the measurement of the intermediate effect of CSR on ICQ and CFP was not clear in the regression model. 


\subsection{Suggestions}

Based on the limitations, there are several extensions for future researchers. Since there is only a limited amount of scholars figuring out the mediator function of CSR within ICQ-CFP relationship, and lots of topics deserve future explorations. Otherwise, it is not confident that the intermediate is CSR or ICQ regarding in different industries. Besides, the concept of internal control could be more precise due to the different characteristic of industry, various development processes of different countries. Finding out the possible relationships within the similar industry is worthy. Also, this research only uses a single variable to reflect $\mathrm{CFP}$, the future studies are encouraged to employ more and different variables to measure financial performance based on accounting measurement, such as return on equity (ROE), and earnings per share(EPS). To make the results more precisely, future researchers can also use market measures like Tobin's Q. In this way, future studies can compare the difference of the above three indicators and better build up a clearer model.

\section{References}

1. Ashbaugh-Skaife, H., Collins, D., Kinney JR, W. and Lafond, R. (2009). The Effect of SOX Internal Control Deficiencies on Firm Risk and Cost of Equity. Journal of Accounting Research, 47(1), pp.1-43.

2. Aupperle, K., Carroll, A. and Hatfield, J. (1985). An Empirical Examination of the Relationship Between Corporate Social Responsibility and Profitability. Academy of Management Journal, 28(2), pp.446-463.

3. Beneish, M., Billings, M. and Hodder, L. (2008). Internal Control Weaknesses and Information Uncertainty. The Accounting Review, 83(3), pp.665-703.

4. Bowman, E. and Haire, M. (1975). A Strategic Posture Toward Corporate Social Responsibility. California Management Review, 18(2), pp.49-58.

5. Brummer, J. (1991). Corporate Responsibility and Legitimacy: An Inter Disciplinary Analysis. New York Greenwood Press, pp.85-101.

6. Chen, Y. and Ma, L. (2005). Empirical Study on Social Responsibility Accounting Information Market Response of Listed Companies in China. Accounting Research, (11), pp.76-81.

7. Doyle, J., Ge, W. and McVay, S. (2007). Accruals Quality and Internal Control Over Financial Reporting. SSRN Electronic Journal.

8. Friedman, M. (1970). The social responsibility of business is to increase its profits. New York Times Magazine, $13,32-33$.

9. Freeman, R. (1984). Strategic management: a stakeholder approach. Boston: Pitman.

10. Ge, W. and McVay, S. (2005). The Disclosure of Material Weaknesses in Internal Control after the SarbanesOxley Act. Accounting Horizons, 19(3), pp.137-158.

11. Knight, A., Worosz, M. and Todd, E. (2007). Serving food safety: consumer perceptions of food safety at restaurants. International Journal of Contemporary Hospitality Management, 19(6), pp.476-484.

12. Kong, Y. and Li, J. (2010). A Study on the Correlation between Corporate Social Responsibility and Financial Performance - A Case Study of Shanghai A-share Manufacturing Industry. Journal of Finance and Economics Monthly, (15), pp.14-16.

13. Li, Z. and Xiang, R. (2007). Research on the Definition, Measurement Method and Present Situation of Information Disclosure of Corporate Social Responsibility in China. Accounting research, (7), pp.3-11.

14. McWilliams, A. and Siegel, D. (2000). Corporate social responsibility and financial performance: correlation or misspecification? Strategic Management Journal, 21(5), pp.603-609.

15. Mitchell, F. (2007). Sarbanes Oxley Section 404: can material weakness be predicted and modeled? An examination of the variables of the ZETA model in prediction of material weakness. Current HKU staff and students. The University of Hong Kong.

16. Preston, L. and O'Bannon, D. (1997). The Corporate Social-Financial Performance Relationship. Business 85 Society, 36(4), pp.419-429.

17. Shen, H. (2005). A Study on the Relationship between Corporate Social Responsibility and Corporate Financial Performance: An Analysis Based on Stakeholder Theory. Master. Xiamen University.

18. Tang, X. (2012). An Analysis of the Correlation between Internal Control and Profitability of Listed Companies. Green Finance and Accounting, (03), pp.34-37. 
19. Tao, R. (2012). Research on Social Responsibility and Financial Performance of Multinational Oil Company. Master. East China Normal University.

20. Tseng, C. (2007). Internal Control and Enterprise Risk. Master. University of Society.

21. Zheng, S., Xu, G., Deng, K. and Wang, J. (2009). A Study on the Types, the Influencing Factor and the Effect of Internal Control Structure. Auditing Research, (01), pp.34-37. 